\title{
Factorial Aerobic Scope Is Independent of Temperature and Primarily Modulated by Heart Rate in Exercising Murray Cod (Maccullochella peelii peelii)
}

\author{
T. D. Clark ${ }^{1, \star}$ \\ T. Ryan ${ }^{2}$ \\ B. A. Ingram ${ }^{3}$ \\ A. J. Woakes ${ }^{4}$ \\ P. J. Butler ${ }^{4}$ \\ P. B. Frappell ${ }^{1, \dagger}$ \\ ${ }^{1}$ Adaptational and Evolutionary Respiratory Physiology \\ Laboratory, Department of Zoology, La Trobe University, \\ Melbourne, Victoria 3086, Australia; ${ }^{2}$ Freshwater Ecology \\ Division, Arthur Rylah Institute, Heidelberg, Victoria 3084, \\ Australia; ${ }^{3}$ Department of Primary Industries, Marine and \\ Freshwater Resources Institute, Eildon, Victoria 3713, \\ Australia; ${ }^{4}$ School of Biosciences, University of Birmingham, \\ Birmingham B15 2TT, United Kingdom
}

Accepted 7/6/2004; Electronically Published 5/3/2005

\begin{abstract}
Several previous reports, often from studies utilising heavily instrumented animals, have indicated that for teleosts, the increase in cardiac output $\left(\dot{V}_{\mathrm{b}}\right)$ during exercise is mainly the result of an increase in cardiac stroke volume $\left(V_{\mathrm{S}}\right)$ rather than in heart rate $\left(f_{\mathrm{H}}\right)$. More recently, this contention has been questioned following studies on animals carrying less instrumentation, though the debate continues. In an attempt to shed more light on the situation, we examined the heart rates and oxygen consumption rates $\left(\dot{\mathrm{Mo}}_{2}\right.$; normalised to a mass of $1 \mathrm{~kg}$, given as $\dot{\mathrm{MO}}_{2 \mathrm{~kg}}$ ) of six Murray cod (Maccullochella peelii peelii; mean mass $\pm \mathrm{SE}=1.81 \pm 0.14 \mathrm{~kg}$ ) equipped with implanted $f_{\mathrm{H}}$ and body temperature data loggers. Data were determined during exposure to varying temperatures and swimming speeds to encompass the majority of the biological scope of this species. An increase in body temperature $\left(T_{\mathrm{b}}\right)$ from $14^{\circ} \mathrm{C}$ to $29^{\circ} \mathrm{C}$ resulted in linear increases in $\dot{M}_{2 \mathrm{~kg}}\left(26.67-41.78 \mu \mathrm{mol} \mathrm{min}{ }^{-1}\right.$ $\left.\mathrm{kg}^{-1}\right)$ and $f_{\mathrm{H}}\left(22.3-60.8\right.$ beats $\left.\mathrm{min}^{-1}\right)$ during routine exercise but a decrease in the oxygen pulse (the amount of oxygen
\end{abstract}

*E-mail: timothy.clark@latrobe.edu.au.

${ }^{\dagger}$ Corresponding author; e-mail: p.frappell@latrobe.edu.au.

Physiological and Biochemical Zoology 78(3):347-355. 2005. (C) 2005 by The University of Chicago. All rights reserved. 1522-2152/2005/7803-4043\$15.00 extracted per heartbeat; $\left.1.28-0.74 \mu \mathrm{mol} \mathrm{beat}{ }^{-1} \mathrm{~kg}^{-1}\right)$. During maximum exercise, the factorial increase in $\dot{M o}_{2 \mathrm{~kg}}$ was calculated to be 3.7 at all temperatures and was the result of temperature-independent 2.2- and 1.7-fold increases in $f_{\mathrm{H}}$ and oxygen pulse, respectively. The constant factorial increases in $f_{\mathrm{H}}$ and oxygen pulse suggest that the cardiovascular variables of the Murray cod have temperature-independent maximum gains that contribute to maximal oxygen transport during exercise. At the expense of a larger factorial aerobic scope at an optimal temperature, as has been reported for species of salmon and trout, it is possible that the Murray cod has evolved a lower, but temperature-independent, factorial aerobic scope as an adaptation to the largely fluctuating and unpredictable thermal climate of southeastern Australia.

\section{Introduction}

For all vertebrates, the Fick principle for oxygen convection by blood describes the rate of oxygen uptake $\left(\dot{M O}_{2}\right)$ as a function of cardiac output $\left(\dot{V}_{\mathrm{b}}\right)$ and tissue oxygen extraction $\left(\mathrm{C}_{\mathrm{a}} \mathrm{O}_{2}-\mathrm{C}_{\overline{\mathrm{v}}} \mathrm{O}_{2}\right)$, where $\mathrm{C}_{\mathrm{a}} \mathrm{O}_{2}$ is the oxygen content of arterial blood and $\mathrm{C}_{\overline{\mathrm{V}}} \mathrm{O}_{2}$ is the oxygen content of mixed venous blood. This is formalised by the equation

$$
\dot{\mathrm{Mo}_{2}}=\dot{V}_{\mathrm{b}} \times\left(\mathrm{C}_{\mathrm{a}} \mathrm{O}_{2}-\mathrm{C}_{\overline{\mathrm{V}}} \mathrm{O}_{2}\right) .
$$

As cardiac output is the product of heart rate $\left(f_{\mathrm{H}}\right)$ and stroke volume $\left(V_{\mathrm{S}}\right)$, the equation can also be written as

$$
\dot{\mathrm{Mo}_{2}}=f_{\mathrm{H}} \times V_{\mathrm{S}} \times\left(\mathrm{C}_{\mathrm{a}} \mathrm{O}_{2}-\mathrm{C}_{\overline{\mathrm{V}}} \mathrm{O}_{2}\right) .
$$

The product of $V_{\mathrm{S}}$ and $\left(\mathrm{C}_{\mathrm{a}} \mathrm{O}_{2}-\mathrm{C}_{\overline{\mathrm{V}}} \mathrm{O}_{2}\right)$ and of $\dot{M o}_{2} / f_{\mathrm{H}}$ is known as the oxygen pulse, so by calculating the oxygen pulse from $\dot{\mathrm{Mo}}_{2}$ and $f_{\mathrm{H}}$, it is possible to determine the relative contributions of $f_{\mathrm{H}}$ and of $V_{\mathrm{S}}\left(\mathrm{C}_{\mathrm{a}} \mathrm{O}_{2}-\mathrm{C}_{\overline{\mathrm{V}}} \mathrm{O}_{2}\right)$ to the increased delivery of oxygen to the metabolising tissues during exercise. Thus, if $f_{\mathrm{H}}$ rather than oxygen pulse primarily contributes to the change in $\dot{M o}_{2}$, then $f_{\mathrm{H}}$ and not $V_{\mathrm{S}}$ is the primary cause of the modulation in $\dot{V}_{\mathrm{b}}$.

A number of studies, primarily restricted to the salmonids, have suggested that teleosts modulate $\dot{V}_{\mathrm{b}}$, and hence aerobic scope, during increased activity primarily through changes in 
$V_{\mathrm{S}}$ rather than $f_{\mathrm{H}}$ (Stevens and Randall 1967; Kiceniuk and Jones 1977; Farrell 1991; Kolok and Farrell 1994). Many such studies used fish that were heavily instrumented and were most likely surgically stressed due to insufficient recovery periods, and the influence of postoperative stress has been recently reported to alter the relationship between cardiovascular variables in rainbow trout (Oncorhynchus mykiss), chinook salmon (Oncorhynchus tshawytscha; Thorarensen et al. 1996 and references within), yellowfin tuna (Thunnus albacares; Korsmeyer et al. 1997), and Atlantic cod (Gadus morhua; Webber et al. 1998).

The contention that $\dot{V}_{\mathrm{b}}$ in teleosts is modulated primarily through changes in $V_{\mathrm{S}}$ is not supported by studies on species such as northern pike (Esox lucius; Armstrong 1986, 1998), Atlantic salmon (Salmo salar; Lucas 1994), and, more recently, species of trout (Altimiras and Larsen 2000; Brodeur et al. 2001; Beaumont et al. 2003). It is more likely, therefore, that cardiac frequency modulation is more prominent among teleosts during increases in $\mathrm{Mo}_{2}$, as it is in other vertebrates, than many previous studies imply. Our study used implantable $f_{\mathrm{H}}$ data loggers and swimming respirometry to examine $f_{\mathrm{H}}$ and $\dot{\mathrm{MO}}_{2}$ in the Murray cod (Maccullochella peelii peelii [Mitchell]), which is predominantly a sedentary, sit-and-wait predator and belongs to a hitherto unstudied family of teleosts (family Percichthyidae).

We wished, therefore, to determine if changes in aerobic scope were mainly correlated with changes in $f_{\mathrm{H}}$ or oxygen pulse; if the former were true, then $\dot{V}_{\mathrm{b}}$ must be modulated primarily by increases in $f_{\mathrm{H}}$. Further, because temperature is known to influence the cardiometabolic parameters of ectotherms (e.g., Satchell 1991; Korsmeyer et al. 1997; Butler et al. 2002), the relationship between $f_{\mathrm{H}}$ and $\dot{\mathrm{Mo}}_{2}$ was examined over a range of acute temperature changes similar to those observed in some natural environments of this species in southeastern Australia.

\section{Material and Methods}

\section{Animals}

Data were obtained from a total of six Murray cod with a mean body mass, $M_{\mathrm{b}}( \pm \mathrm{SE}$ of the mean), of $1.81 \pm 0.14 \mathrm{~kg}$ and a mean length of $485 \pm 9 \mathrm{~mm}$ (Animal Ethics Code 99/42L). All animals were obtained from the Department of Primary Industries, Marine and Freshwater Resources Institute (MAFRI) hatchery at Snobs Creek, Victoria, Australia, where they had been raised indoors. Fish were kept individually in 1,000-L tanks through which there was a continual turnover of filtered freshwater obtained from the nearby creek $(>95 \%$ oxygen saturation; average daily temperature range $21^{\circ}-26^{\circ} \mathrm{C}$ ).

\section{Surgery}

Fish were anaesthetised using approximately $0.25 \mathrm{~mL} \mathrm{~L}^{-1}$ alfaxalone (Alfaxan-CD, Jurox, New South Wales) before surgery, and exposure was continued throughout. Fish were weighed, measured, and positioned upside down between two foam pads on an operating table. The skin and underlying tissue layers of the abdomen were opened along a 3-4- $\mathrm{cm}$ incision along the ventral midline. Sterilised $f_{\mathrm{H}}$ and body temperature $\left(T_{\mathrm{b}}\right)$ data loggers (HRTDL; see Woakes et al. 1995 for construction details) were implanted so that one electrode (length $70 \mathrm{~mm}$ ) was positioned close to the heart and the other (length $30 \mathrm{~mm}$ ) was along the side of the HRTDL in the abdominal cavity. The body of the HRTDL $(40 \mathrm{~mm} \times 30 \mathrm{~mm} \times 15 \mathrm{~mm})$ was fixed in place with one or two sutures of surgical silk (Ethicon, Norderstedt, Germany) through the body wall. Correct positioning of the HRTDL could be determined through the use of a radio receiver that detected short-pulse low-power radio frequency transmissions emitted by the HRTDL on each QRS wave of the electrocardiogram. The muscle layer and skin were individually closed with nondissolvable surgical suture, and the wound was swabbed with iodine antiseptic after surgery. Loggers recorded $f_{\mathrm{H}}$ and $T_{\mathrm{b}}$ every 5 -s and 30-s period, respectively, and the time at which the HRTDL was implanted was noted to the nearest minute.

Following surgery, fish were placed in a small recovery tank to regain full consciousness (approximately $20 \mathrm{~min}$ ) before being released into a 1,000-L holding tank. Water in the holding tank was treated with $5 \mathrm{~g} \mathrm{~L}^{-1}$ salt and $2 \mathrm{mg} \mathrm{L}^{-1}$ methylene blue as a prophylactic treatment to aid recovery of the fish. After $24 \mathrm{~h}$, salt and methylene blue were flushed from the holding tank by the introduction of a continuous flow of freshwater (7.5-10 $\left.\mathrm{L} \mathrm{min}^{-1}\right)$ that was maintained throughout the remainder of the experiment. All fish survived the procedure. The fish were fed every other day and given $14 \mathrm{~d}$ to recover before experiments. Fish were not fed for a 2-d period before they were used for experiments, to allow full gut evacuation (B. Ingram, unpublished data); hence, we avoided incorporating the influence of specific dynamic action into the measurements.

\section{Swim Flume Apparatus}

Measurements of $\mathrm{MO}_{2}$ were determined in a purpose-built closed-system swimming flume with a water volume of $39 \mathrm{~L}$. Fish were introduced into the flume through an opening at the top of the swimming chamber that was afterward sealed with a screw cap. The fish were restricted to the transparent swimming chamber (diameter $150 \mathrm{~mm}$ ) by a removable mesh grill (10 $\times 10-\mathrm{mm}$ grid) positioned at either end of the chamber, and the anterior end of the swimming chamber was equipped with narrow tubes to assist in achieving a uniform flow. The chamber was completely covered with black sheeting except for a $15-\mathrm{mm}$ gap at the dorsal end that was used to monitor the well-being of the fish.

The flow of water through the flume was generated using a closed-system pool pump (model PACR 300, Davey, Scoresby, Victoria), and the flow of water through the swimming chamber 
Table 1: Polynomial regression relationships of mass-independent rate of oxygen consumption $\left(\dot{\mathrm{Mo}}_{2 \mathrm{~kg}}, \mu \mathrm{mol} \mathrm{min} \mathrm{mg}^{-1} \mathrm{~kg}^{-1}\right)$ and heart rate $\left(f_{\mathrm{H}}\right.$, beats $\left.\min ^{-1}\right)$ against water speed (body lengths $\mathrm{s}^{-1}$ ) for Murray cod at established mean temperatures (temperature range indicated)

\begin{tabular}{|c|c|c|c|c|c|c|c|}
\hline$y, T_{\mathrm{b}}\left({ }^{\circ} \mathrm{C}\right)$ & $N$ & $n$ & $a$ & $b$ & $c$ & $r^{2}$ & Rest $^{\mathrm{a}}$ \\
\hline \multicolumn{8}{|l|}{$\dot{\mathrm{Mo}}_{2 \mathrm{~kg}}:$} \\
\hline Mean $16.1 \pm .5\left(14^{\circ}-20^{\circ} \mathrm{C}\right)$ & 6 & 19 & 1.270 & .927 & -.356 & .71 & 18.62 \\
\hline Mean $22.0 \pm .3\left(21^{\circ}-24^{\circ} \mathrm{C}\right)$ & 6 & 18 & 1.334 & 1.079 & -.446 & .82 & 21.56 \\
\hline Mean $27.2 \pm .3\left(25^{\circ}-29^{\circ} \mathrm{C}\right)$ & $5^{\mathrm{b}}$ & 24 & 1.427 & .785 & -.266 & .75 & 26.70 \\
\hline \multicolumn{8}{|l|}{$f_{\mathrm{H}}:$} \\
\hline Mean $16.1 \pm .5\left(14^{\circ}-20^{\circ} \mathrm{C}\right)$ & 6 & 19 & 1.259 & .746 & -.363 & .63 & 18.2 \\
\hline Mean $22.0 \pm .3\left(21^{\circ}-24^{\circ} \mathrm{C}\right)$ & 6 & 18 & 1.504 & .574 & -.248 & .50 & 31.9 \\
\hline Mean $27.2 \pm .3\left(25^{\circ}-29^{\circ} \mathrm{C}\right)$ & $5^{\mathrm{b}}$ & 24 & 1.607 & .556 & -.189 & .75 & 40.4 \\
\hline
\end{tabular}

Note. Equations were calculated using data obtained over a speed range of 0.18-1.45 body lengths per second, though the maximum swimming speed for $14^{\circ}-20^{\circ} \mathrm{C}$ was 1.12 body lengths $\mathrm{s}^{-1}$. Regression equations of the form $\log y=a+b U+c U^{2}$, where $U$ is water speed (body lengths per second); $n$ denotes the number of data points forming the regression.

${ }^{\text {a }}$ Predicted value at zero water speed at the mean $T_{\mathrm{b}}$ (see text). Units as described in table title.

${ }^{\mathrm{b}}$ One individual was not measured at a warm temperature due to malfunctioning heating equipment.

could be altered by use of a three-way valve that allowed water to bypass the chamber. The water flow rate through the swimming chamber was calibrated with a flow probe (model OSSPC1) that determined flow over a 30-s period according to the number of revolutions of a $50-\mathrm{mm}$ propeller positioned in the centre of the swimming chamber. A maximum water speed of $0.50 \mathrm{~m} \mathrm{~s}^{-1}$ was achieved through the empty swimming chamber when the bypass was completely closed.

Water temperature and oxygen saturation in the flume were continuously monitored using a calibrated oxygen and temperature electrode (model 600XLM, Yellow Springs Industries [YSI], Yellow Springs, OH; employs a rapid pulse system that removes flow dependence and thus does not create a boundary layer at the membrane surface) positioned inside the flume. Data were logged at one sample per $10 \mathrm{~s}$ to a computer using Ecowatch software (EcoWin, Yellow Springs, OH). An empty chamber was regularly used as a blank as a precaution to ensure that microbial respiration was not altering $\dot{M}_{2}$ measurements, though the reduction in oxygen saturation of the water passing through the chamber was in all cases negligible.

\section{Protocol}

Rate of oxygen consumption and $f_{\mathrm{H}}$ measurements were obtained for all six fish at three water temperatures (except for one individual, for which measurements were performed only at two temperatures due to malfunctioning heating equipment). Between measurements, the flume was continuously flushed with oxygenated water from the holding tank at the desired experimental temperature (the temperature of the water was established at least $18 \mathrm{~h}$ before experimentation), and fish remained predominantly quiescent when they were not swim- ming against high water flows. During each 10-12-min $\dot{M}_{2}$ measurement, the flume was sealed, with care taken to remove any obvious bubbles from the system. Measurements were ceased and the flume reopened to freshwater before oxygen saturation in the flume fell to $75 \%$.

Fish were introduced to the flume and given $30 \mathrm{~min}$ to acclimate, and then the speed was increased incrementally until the fish began to lose position; the speed was then reduced to a speed at which the fish could hold station, and the $\dot{M}_{2}$ measurement commenced. The maximum swimming speed ranged, depending primarily on temperature, between 0.32 and $0.50 \mathrm{~m} \mathrm{~s}^{-1}$. It was our intention not to quantify maximum swimming speed but to ensure that the fish were swimming at maximum sustainable aerobic speeds; maximum aerobic contributions previously have been shown to occur at $80 \%-90 \%$ of maximum swimming speed in salmonids and at 30\%-50\% in cyprinids (Jones 1982).

This protocol took account of the fact that fish metabolism was elevated when the fish was initially introduced into the flume. Upon conclusion of the maximum $\dot{\mathrm{Mo}}_{2}$ measurement, the flume was opened and the fish remained in the flume on a low water speed $\left(0.02 \mathrm{~m} \mathrm{~s}^{-1}\right)$ for at least $7 \mathrm{~h}$ to allow cardiovascular variables to decrease and stabilise. Following this period, $\dot{\mathrm{Mo}}_{2}$ was determined while the fish swam at a comfortable water speed similar to that generally encountered in the holding tanks ( $0.06 \mathrm{~m} \mathrm{~s}^{-1}$, termed "routine exercise"). The design of the flume did not allow the measurement of $\dot{M o}_{2}$ while the fish was at complete rest at zero water speed. Finally, $\dot{\mathrm{Mo}}_{2}$ measurements were determined at a speed approximately midway between the speeds used for routine and maximum exercise $\left(0.15-0.23 \mathrm{~m} \mathrm{~s}^{-1}\right)$. Swimming speed of the fish in the flume was subsequently corrected for the solid blocking effect 
of each individual fish using the method given by Jones et al. (1974).

The slope of the decline in oxygen saturation of water with time when the flume was sealed was used to calculate $\dot{M}_{2}$ (given at STPD). The mean $T_{\mathrm{b}}$ and $f_{\mathrm{H}}$ for a trial were determined during the last half of the period used to determine the $\mathrm{Mo}_{2}$ reading. At the end of the trial, fish were returned to their holding tanks, and the temperature of the tank water was altered by adjusting temperature-regulating elements. The desired temperature $\left( \pm 2^{\circ} \mathrm{C}\right)$ was influenced by the daily temperature fluctuations of the creek water and was typically reached within $2.5 \mathrm{~h}$, after which fish were given a further $18 \mathrm{~h}$ to acclimate before experimentation. For some individuals, $\mathrm{Mo}_{2}$ measurements were determined at additional speeds and additional temperatures on a separate occasion (see Table 1). At the conclusion of experimentation, the HRTDL was removed using the same procedure as during implantation.

\section{Data Analysis and Statistics}

Following $\log _{10}$-transformation of the data, least squares regressions were used to determine the relationships between $f_{\mathrm{H}}$ and $\dot{M}_{2}$ against $M_{\mathrm{b}}$ (covariate) across all temperatures for routine and maximum exercise. A test for homogeneity of slopes revealed no difference between slopes for routine and maximum exercise for each variable $(P>0.5)$. The common regression coefficient was computed $\left(f_{\mathrm{H}}, b=0.17, P=0.740 ; \dot{M o}_{2}, b=0.90, P<\right.$ 0.001 ), and, in the case where this was significantly different from 0 , it was used to standardise all data for the covariate (see Packard and Boardman 1999 for full explanation). Corrections for the covariate $\left(\log M_{\mathrm{b}}\right.$ in this case) are normally made to the grand mean but, given that the data have been log transformed, proportionality across $M_{\mathrm{b}}$ is maintained and adjustments to $\dot{M}_{2}$ values were therefore made to $\mathrm{a} M_{\mathrm{b}}$ of $1 \mathrm{~kg}$ (denoted by $\left.\dot{\mathrm{M}}{ }_{2 \mathrm{~kg}}\right)$.

Least squares regressions were used to determine the relationships between $\dot{M o}_{2 \mathrm{~kg}}, f_{\mathrm{H}}$, and oxygen pulse (determined from eq. [2]) for the group data against $T_{\mathrm{b}}$. Differences between group regressions, where appropriate, were tested with ANCOVA. Stepwise multiple linear regression was used to determine the interactions between $T_{\mathrm{b}}, f_{\mathrm{H}}$, and $\dot{\mathrm{Mo}}_{2 \mathrm{~kg}}$. Significance was considered at $P<0.05$. Data are presented as mean $\pm \mathrm{SE}$ of the mean, and $\log _{10}$ is used throughout for logarithmic transformations. $N=$ number of animals; $n=$ number of data points.

\section{Results}

The period immediately following surgery typically was characterised by a large tachycardia. Heart rate declined rapidly during the first hour, after which the decline slowed. Stable low values were obtained approximately $24 \mathrm{~h}$ postsurgery. Following


Figure 1. Diurnal fluctuations of heart rate $\left(f_{\mathrm{H}}\right)$ and body temperature $\left(T_{\mathrm{b}}\right)$ of unfed Murray cod while exposed to natural fluctuations in water temperature. We observed that body temperature remained in unity with water temperature at all times, and $f_{\mathrm{H}}$ displayed a clear dependence on $T_{\mathrm{b}}$.

this, fish remained predominantly quiescent during periods of nonfeeding in the holding tanks, and $T_{\mathrm{b}}$ remained in unity with water temperature at all times. The dependence of $f_{\mathrm{H}}$ on $T_{\mathrm{b}}$ becomes clearly evident when examining $f_{\mathrm{H}}$ traces of individual fish in holding tanks when exposed to the diurnal water temperature fluctuations of Snobs Creek (Fig. 1).

During swimming experiments, both $f_{\mathrm{H}}$ and $\dot{\mathrm{Mo}}_{2 \mathrm{~kg}}$ increased with water speed at all temperatures throughout the range of $14^{\circ}-29^{\circ} \mathrm{C}$. Heart rate and $\dot{\mathrm{Mo}}_{2 \mathrm{~kg}}$ during exercise were best related to swimming speed and temperature in accordance with the polynomial regression equations given in Table 1 . Fish below approximately $20^{\circ} \mathrm{C}$ were not able to sustain swimming speeds in excess of 1.12 body lengths $\mathrm{s}^{-1}$, whereas above $20^{\circ} \mathrm{C}$, some fish were able to maintain a maximum swimming speed of up to 1.45 body lengths $\mathrm{s}^{-1}$ for the duration of the swimming experiment (approximately 10-12 $\mathrm{min}$ ).

An increase in $T_{\mathrm{b}}$ resulted in significant increases both in $\dot{M o}_{2 \mathrm{~kg}}$ (Fig. 2a) and $f_{\mathrm{H}}$ (Fig. 2b) and a significant decrease in oxygen pulse (Fig. 2c) regardless of activity state. Regression 




Figure 2. Relationship of (a) mass-independent rate of oxygen consumption $\left(\dot{\mathrm{Mo}}_{2 \mathrm{~kg}}\right),(b)$ heart rate $\left(f_{\mathrm{H}}\right)$, and $(c)$ oxygen pulse with body temperature $\left(T_{\mathrm{b}}\right)$ for Murray cod. The regressions of all three variables displayed statistically similar slopes at routine exercise (open circles and solid line) and maximum exercise (solid circles and solid line; $P>$ 0.05 ), and all regressions for maximum exercise had significantly elevated intercepts compared with those for routine exercise. Also indicated for $f_{\mathrm{H}}$ are values (triangles; mean $\pm \mathrm{SE}$ ) and the associated regression line (bold line) determined for animals fasted for $2 \mathrm{~d}$ and resting in holding tanks. Regression equations are given in Table 2. Further, for each variable the values predicted for zero water speed, calculated using regression equations in Table 1, are indicated (squares), and the associated regression lines (dashed lines) are shown for $\dot{\mathrm{MO}}_{2 \mathrm{~kg}}$ and oxygen pulse. equations and $Q_{10}$ values for each variable at routine exercise and maximum exercise are given in Table 2. The elevation of the regression for each variable at maximum exercise was greater than for that at routine exercise $(P<0.05$; Table 2$)$. The slope of the regression at routine exercise was in all cases statistically similar to that at maximum exercise $(P>0.05$; Fig. 2$)$, indicating a constancy of the factorial scope (given, in this instance, as the ratio of the elevations for maximum exercise to routine exercise) for each variable over the temperature range, the difference in elevation being 2.4-, 1.7-, and 1.5-fold for $\dot{M o}_{2 \mathrm{~kg}}, f_{\mathrm{H}}$, and oxygen pulse, respectively.

Interestingly, if the values of $f_{\mathrm{H}}$ are predicted for zero water speed (i.e., animals at rest) from the equations given in Table 1 they compare favourably to the values measured from undisturbed animals in holding tanks before experimentation (cf. square symbols and bold regression, Fig. 2b). By employing the same principle for $\dot{M o}_{2 \mathrm{~kg}}$, values of resting $\dot{M}_{2 \mathrm{~kg}}$ may be predicted for zero water speed at the mean $T_{\mathrm{b}}$ 's indicated in Table $1\left(16.1^{\circ} \mathrm{C}, 18.62 \mu \mathrm{mol} \mathrm{min}{ }^{-1} \mathrm{~kg}^{-1}\right.$; $22.0^{\circ} \mathrm{C}, 21.56 \mu \mathrm{mol} \mathrm{min}{ }^{-1} \mathrm{~kg}^{-1} ; 27.2^{\circ} \mathrm{C}, 26.70 \mu \mathrm{mol} \mathrm{min}{ }^{-1}$ $\mathrm{kg}^{-1}$ ); thus, a regression for resting $\dot{\mathrm{Mo}}_{2 \mathrm{~kg}}$ (and, by calculation, oxygen pulse) can be predicted (dashed regressions; Fig. $2 a, 2 c)$. Given that proportionality remains the same between the regression of resting $\dot{\mathrm{Mo}}_{2 \mathrm{~kg}}$ and that of maximum $\dot{M o}_{2 \mathrm{~kg}}$ (mean slope 0.014), a factorial aerobic scope (maximum $\dot{M}_{2 \mathrm{~kg}}$ : resting $\dot{\mathrm{Mo}}_{2 \mathrm{~kg}}$ ) of 3.7 can be predicted throughout the temperature range, resulting from factorial scopes of $f_{\mathrm{H}}$ and oxygen pulse of 2.2 and 1.7, respectively.

The log-log relationship between $f_{\mathrm{H}}$ and $\dot{M}_{2 \mathrm{~kg}}$ for routine exercise and maximum exercise is illustrated in Figure 3. The parallel slopes of the regressions (solid lines) suggest a systematic contribution of both $f_{\mathrm{H}}$ and oxygen pulse from routine exercise to maximum exercise across the $T_{\mathrm{b}}$ range of $14^{\circ}-29^{\circ} \mathrm{C}$. Also displayed in Figure 3 are the relationships that exist between $f_{\mathrm{H}}$ and $\dot{\mathrm{Mo}}_{2 \mathrm{~kg}}$ during exercise at three typical temperatures of $14.0^{\circ} \mathrm{C}, 20.5^{\circ} \mathrm{C}$, and $29.0^{\circ} \mathrm{C}$ (dashed lines), as predicted using the group multiple regression equation that relates $T_{\mathrm{b}}, f_{\mathrm{H}}$, and $\dot{\mathrm{Mo}}{ }_{2 \mathrm{~kg}}$ :

$$
\log \dot{M}_{2 \mathrm{~kg}}=-6.75+1.2 \times \log f_{\mathrm{H}}+1,895.5 \times\left(1 / T_{\mathrm{b}}\right)
$$

where $T_{\mathrm{b}}$ is in degrees Kelvin and $n=58$. Although $\log f_{\mathrm{H}}$ was the most prominent contributor to the prediction of $\dot{M}_{2 \mathrm{~kg}}\left(r^{2}=0.56\right)$, stepwise regression revealed that the addition of $1 / T_{\mathrm{b}}$ significantly strengthened the relationship $\left(r^{2}=\right.$ $0.67)$.

\section{Discussion}

The main disadvantage of surgical implantation of the HRTDL is that, due to the invasive nature of the surgery, there may be a considerable period of postoperative stress, during which time 
Table 2: Linear regression relationships of mass-independent rate of oxygen consumption $\left(\dot{M}_{2 \mathrm{~kg}}, \mu \mathrm{mol} \mathrm{min}{ }^{-1} \mathrm{~kg}^{-1}\right)$, heart rate $\left(f_{\mathrm{H}}\right.$, beats $\left.\min ^{-1}\right)$, and oxygen pulse $\left(\mu \mathrm{mol}\right.$ beat $\left.{ }^{-1} \mathrm{~kg}^{-1}\right)$ versus $T_{\mathrm{b}}$ at routine exercise and maximum exercise for Murray cod

\begin{tabular}{lcccccccc}
\hline$y$ & $n$ & $a$ & $b$ & $S_{a}$ & $S_{b}$ & $S_{Y X}$ & $r^{2}$ & $\mathrm{Q}_{10}$ \\
\hline $\mathrm{Mo}_{2 \mathrm{~kg}}:$ & & & & & & & & \\
$\quad$ Routine exercise & 17 & $1.244^{*}$ & .013 & .070 & .003 & .064 & .56 & 1.35 \\
$\quad$ Maximum exercise & 20 & 1.611 & .014 & .069 & .003 & .055 & .55 & 1.38 \\
$f_{\mathrm{H}}:$ & & & & & & & & \\
$\quad$ Rest & 25 & $.870^{*}$ & .027 & .049 & .002 & .064 & .86 & 1.86 \\
$\quad$ Routine exercise & 17 & $.943^{*}$ & .029 & .075 & .003 & .069 & .85 & 1.95 \\
$\quad$ Maximum exercise & 20 & 1.061 & .034 & .063 & .003 & .050 & .90 & 2.19 \\
Oxygen pulse: & & & & & & & & \\
$\quad$ Routine exercise & 17 & $.332^{*}$ & -.016 & .076 & .003 & .070 & .61 & .69 \\
$\quad$ Maximum exercise & 20 & .578 & -.020 & .093 & .004 & .075 & .59 & .63 \\
\hline
\end{tabular}

Note. Regressions were determined across a temperature range of approximately $14^{\circ}-29^{\circ} \mathrm{C}$. $\mathrm{Q}_{10}$ values for each variable are also presented. Regression equations of the form $\log y=a+b T_{\mathrm{b}} ; n$ denotes the number of data points forming the regression. $N=6$; $\mathrm{Q}_{10}$ values were determined from the slopes of the regressions according to the equation $\mathrm{Q}_{10}=10^{(b \times 10)}$.

* Significantly lower than intercept of regression for maximum exercise $(P<0.05)$; for each variable there were no significant differences in the slopes of the regressions between rest, routine exercise, and maximum exercise $(P>0.05) ; S_{a}=\mathrm{SE}$ of $a ; S_{b}=\mathrm{SE}$ of $b ; S_{Y X}=\mathrm{SE}$ of estimate.

data obtained need to be treated with caution (Lucas et al. 1993). Indeed, observations from our study indicate that recovery periods less than approximately $24 \mathrm{~h}$ are insufficient to obtain resting $f_{\mathrm{H}}$ values for Murray cod, a finding that is supported by results obtained for several other fish species (Houston et al. 1973; Webber et al. 1998; Altimiras and Larsen 2000). In contrast, studies on some species have reported that postinstrumentation recovery periods of only $12 \mathrm{~h}$ are sufficient (e.g., Priede and Young 1977; Lucas et al. 1991). Nevertheless, $f_{\mathrm{H}}$ data from our study for fish in holding tanks were used only after $14 \mathrm{~d}$ of recovery; thus, we are confident that postoperative stress did not influence the results of this study. Further, we are confident that the large ranges of $T_{\mathrm{b}}, f_{\mathrm{H}}$, and $\dot{M}_{2}$ investigated in this study encompass the majority of the biological scope for the species, given the knowledge of thermal habitat and activity of this species in the natural environment (Rowland 1989, 1998; Koehn et al. 1993).

Heart rate of ectothermic animals is often temperature dependent because of increased membrane permeability of the pacemaker fibres and change in the vagal tone (Satchell 1991). Indeed, the increase in $\dot{M o}_{2 \mathrm{~kg}}$ with $T_{\mathrm{b}}$ for Murray cod was associated with an increase in $f_{\mathrm{H}}$ and a slight, yet significant, decrease in oxygen pulse. A similar inverse relationship as that for oxygen pulse and temperature has been reported for $V_{\mathrm{S}}$ and temperature of yellowfin tuna $\left(\mathrm{Q}_{10}=0.8\right.$; Korsmeyer et al. 1997) and rainbow trout $\left(Q_{10}=0.7\right.$; reworked data from Farrell et al. 1996) and is thought to be the result of a reduction in both filling time and force of contraction at higher temperatures (Farrell and Jones 1992).
It is interesting to note for the Murray cod that temperature offsets the linear regression that describes the relationship between $f_{\mathrm{H}}$ and $\dot{\mathrm{MO}}_{2}$ at various levels of exercise (Fig. 3, dashed lines). A similar occurrence has been reported for the Atlantic cod (Claireaux et al. 1995), though in that study, despite relatively strong correlations between $f_{\mathrm{H}}$ and $\dot{M o}_{2}$, the small change in $f_{\mathrm{H}}$ observed during exercise led the authors to dismiss it as a major contributor to increased cardiac delivery in Atlantic cod. In contrast, reports for pike (Armstrong 1986) and Atlantic salmon (Lucas 1994) at various exercise states indicate that an increase in temperature simply extends the same regression line between $f_{\mathrm{H}}$ and $\dot{\mathrm{Mo}}_{2}$ with maintenance of the intercept. Nevertheless, there have been conflicting reports for teleosts regarding the relative contributions of $f_{\mathrm{H}}$ and $V_{\mathrm{S}}$ to increases in $\dot{V}_{\mathrm{b}}$ and $\dot{\mathrm{Mo}}_{2}$ during exercise (Stevens and Randall 1967; Randall 1968; Kiceniuk and Jones 1977; Farrell 1991; Farrell and Jones 1992; Lucas 1994; Cooke et al. 2002; Beaumont et al. 2003). Even intraspecific reports regarding the percentage contribution of $f_{\mathrm{H}}$ to $\mathrm{Mo}_{2}$ have been highly variable for many teleosts, exemplified by the broad range found for rainbow trout-between 8.7\% (Stevens and Randall 1967) and 49.7\% (Priede and Tytler 1977).

In this context, increases in swimming speed of Murray cod in our study resulted in temperature-dependent increases in $\dot{M}_{2 \mathrm{~kg}}$, which were regulated primarily by increases in $f_{\mathrm{H}}$ as opposed to oxygen pulse. The factorial scope of $f_{\mathrm{H}}$ found for Murray cod throughout the $14^{\circ}-29^{\circ} \mathrm{C}$ temperature range (2.2) agrees favourably to the value of 2.4 obtained for rainbow trout at $15^{\circ} \mathrm{C}$ (Altimiras and Larsen 2000) and the value of $2.0 \mathrm{cal}-$ 


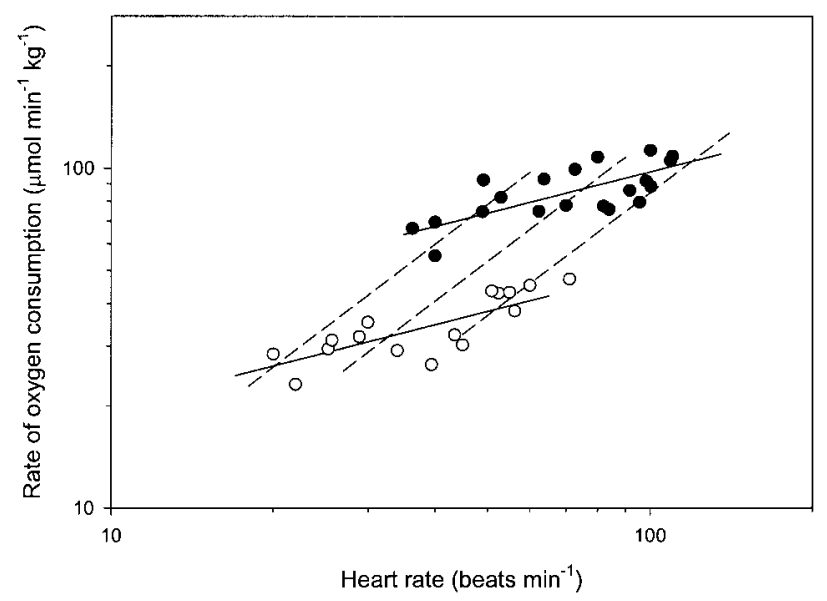

Figure 3. Log-log relationship between mass-independent rate of oxygen consumption $\left(\dot{\mathrm{Mo}}_{2 \mathrm{~kg}}\right)$ and heart rate $\left(f_{\mathrm{H}}\right)$ for Murray cod at routine exercise (open circles) and maximum exercise (solid circles). The slopes of the regressions were statistically similar $(P>0.05)$; thus they were described by a common equation that takes into account activity state: $\log \dot{M o}_{2 \mathrm{~kg}}=0.60+0.40 \times \log f_{\mathrm{H}}+0.29 \times$ state, where "state" was given a value of 1 or 2 to represent routine exercise or maximum exercise, respectively. Predicted relationships (dashed lines) as calculated from the group regression equation (eq. [3]) are included at $14.0^{\circ} \mathrm{C}, 21.5^{\circ} \mathrm{C}$, and $29.0^{\circ} \mathrm{C}$ (from left to right, respectively) to illustrate the linear increase of $\log \dot{M o}_{2 \mathrm{~kg}}$ and $\log f_{\mathrm{H}}$ that occurs with exercise at different body temperatures $\left(T_{\mathrm{b}}\right)$.

culated for yellowfin tuna at $24^{\circ} \mathrm{C}$ (reworked data from Korsmeyer et al. 1997), though it is higher than the value of 1.6 determined for Atlantic cod at $10^{\circ} \mathrm{C}$ (Priede and Tytler 1977). The factorial aerobic scope of 3.7 calculated for Murray cod in our study is within the range for teleosts: greater than that determined for white crappie at $25^{\circ} \mathrm{C}$ (3.0; Parsons and Sylvester 1992), though approximately one-quarter of the value of 15.4 that was determined for sockeye salmon at $15^{\circ} \mathrm{C}$ (Brett and Glass 1973), which is hardly surprising given that Murray cod are sit-and-wait predators whereas salmon have a more active lifestyle (Korsmeyer et al. 1997).

As with any ratio, the factorial aerobic scope is particularly sensitive to changes in the denominator (minimum $\dot{M o}_{2}$ ). Therefore, conclusions resulting from interspecific comparisons of the factorial aerobic scope of the Murray cod remain tentative until measurements of minimum $\dot{M}_{2}$ have been conducted. Nevertheless, it is not so much the amplitude, but rather the independence of temperature, of the factorial aerobic scope of the Murray cod that is of interest in this study. The fact that the factorial aerobic scope remained at 3.7 from $14^{\circ} \mathrm{C}$ to $29^{\circ} \mathrm{C}$ indicates that the absolute increase from rest to maximum exercise increases 3.7-fold for every given increment of temperature. Consequently, the absolute aerobic scope (maximum $\dot{M O}_{2}$ - resting $\dot{\mathrm{Mo}}_{2}$ ) would increase linearly with tem- perature and allow a greater absolute scope for activity at warmer temperatures, which is likely to be the reason why upstream migration for spawning in the natural environment occurs only after water temperature has risen to approximately $20^{\circ} \mathrm{C}$ (Cadwallader and Backhouse 1983; Kailola et al. 1993). In contrast are data for species of salmon (Brett and Glass 1973; Farrell 2002; Lee et al. 2003) and trout (Dickson and Kramer 1971; Taylor et al. 1996) that imply there is a small optimal temperature range within the annual operant range at which $\dot{V}_{\mathrm{b}}$, and thus oxygen consumption rates, has an optimal gain from rest to maximum aerobic exercise.

The constant factorial increases in $f_{\mathrm{H}}$ and oxygen pulse determined for Murray cod suggest that the cardiovascular variables of this species have temperature-independent maximum gains that contribute to maximal oxygen transport during exercise. At the expense of a larger factorial aerobic scope at an optimal temperature, it is possible that the Murray cod has evolved a lower, but temperature-independent, factorial aerobic scope as an adaptation to the largely fluctuating and unpredictable thermal climate of southeastern Australia.

\section{Acknowledgments}

Damien O'Mahony and Justin O’Mahony are thanked for performing the surgery to implant loggers. Staff of the Marine and Freshwater Resources Institute, Snobs Creek, particularly Peter Grant, Peter Boyd, and Peter Ryder, are thanked for their hospitality and support with fish husbandry. T.D.C. was the recipient of an Australian Postgraduate Research Award.

\section{Literature Cited}

Altimiras J. and E. Larsen. 2000. Non-invasive recording of heart rate and ventilation rate in rainbow trout during rest and swimming: fish go wireless! J Fish Biol 57:197-209.

Armstrong J.D. 1986. Heart rate as an indicator of activity, metabolic rate, food intake and digestion in pike, Esox lucius. J Fish Biol 29:207-221.

- 1998. Relationships between heart rate and metabolic rate of pike: integration of existing data. J Fish Biol 52:362368.

Beaumont M.W., P.J. Butler, and E.W. Taylor. 2003. Exposure of brown trout, Salmo trutta, to a sub-lethal concentration of copper in soft acidic water: effects upon gas exchange and ammonia accumulation. J Exp Biol 206:153-162.

Brett J.R. and N.R. Glass. 1973. Metabolic rates and critical swimming speeds of sockeye salmon (Oncorhynchus nerka) in relation to size and temperature. J Fish Res Board Can 30:379-387.

Brodeur J.C., D.G. Dixon, and R.S. McKinley. 2001. Assessment 
of cardiac output as a predictor of metabolic rate in rainbow trout. J Fish Biol 58:439-452.

Butler P.J., P.B. Frappell, T. Wang, and M. Wikelski. 2002. The relationship between heart rate and rate of oxygen consumption in Galapagos marine iguanas (Amblyrhynchus cristatus) at two different temperatures. J Exp Biol 205:19171924.

Cadwallader P.L. and G.N. Backhouse. 1983. A Guide to the Freshwater Fish of Victoria. Victorian Government Printing Office, Melbourne.

Claireaux G., D.M. Webber, S.R. Kerr, and R.G. Boutilier. 1995. Physiology and behaviour of free-swimming Atlantic cod (Gadus morhua) facing fluctuating temperature conditions. J Exp Biol 198:49-60.

Cooke S.J., C.M. Bunt, J.F. Schreer, and D.P. Philipp. 2002. Attachment, validation, and preliminary deployment of ultrasonic heart rate transmitters on largemouth bass, Micropterus salmoides. Aquat Living Resour 15:155-162.

Dickson I.W. and R.H. Kramer. 1971. Factors influencing scope for activity and active and standard metabolism of rainbow trout (Salmo gairdneri). J Fish Res Board Can 28:587-596.

Farrell A.P. 1991. From hagfish to tuna: a perspective on cardiac function in fish. Physiol Zool 64:1137-1164.

- 2002. Cardiorespiratory performance in salmonids during exercise at high temperature: insights into cardiovascular design limitations in fishes. Comp Biochem Physiol 132A:797-810.

Farrell A.P., A.K. Gamperl, J.M.T. Hicks, H.A. Shiels, and K.E. Jain. 1996. Maximum cardiac performance of rainbow trout (Oncorhynchus mykiss) at temperatures approaching their upper lethal limit. J Exp Biol 199:663-672.

Farrell A.P. and D.R. Jones. 1992. The heart. Pp. 1-88 in W.S. Hoar, D.J. Randall, and A.P. Farrell, eds. Fish Physiology. Vol. 12A. Academic Press, San Diego, CA.

Houston A.H., C.L. Czerwinski, and R.J. Wood. 1973. Cardiovascular-respiratory activity during recovery from anaesthesia and surgery in brook trout (Salvelinus fontinalis) and carp (Cyprinus carpio). J Fish Res Board Can 30:1705-1712.

Jones D.R. 1982. Anaerobic exercise in teleost fish. Can J Zool 60:1131-1134.

Jones D.R., J.W. Kiceniuk, and O.S. Bamford. 1974. Evaluation of the swimming performance of several fish species from the Mackenzie River. J Fish Res Board Can 31:1641-1647.

Kailola P.J., M.J. Williams, P.C. Stewart, R.E. Reichelt, A. McNee, and C. Grieve. 1993. Australian Fisheries Resources. Bureau of Resource Sciences, Department of Primary Industries and Energy, and the Fisheries Research and Development Corporation, Canberra, Australia.

Kiceniuk J.W. and D.R. Jones. 1977. The oxygen transport system in trout (Salmo gairdneri) during sustained exercise. J Exp Biol 69:247-260.

Koehn J., J. McKenzie, B. O’Connor, and D. O’Mahony. 1993.
Codwatch. Freshwater Ecology, Department of Conservation, Arthur Rylah Institute, Heidelberg, Victoria.

Kolok A.S. and A.P. Farrell. 1994. Individual variation in the swimming performance and cardiac performance of northern squawfish, Ptychocheilus oregonensis. Physiol Zool 67: 706-722.

Korsmeyer K.E., N. Chin Lai, R.E. Shadwick, and J.B. Graham. 1997. Heart rate and stroke volume contributions to cardiac output in swimming yellowfin tuna: response to exercise and temperature. J Exp Biol 200:1975-1986.

Lee C.G., A.P. Farrell, A. Lotto, M.J. MacNutt, S.G. Hinch, and M.C. Healey. 2003. The effect of temperature on swimming performance and oxygen consumption in adult sockeye (Oncorhynchus nerka) and coho (O. kisutch) salmon stocks. J Exp Biol 206:3239-3251.

Lucas M.C. 1994. Heart rate as an indicator of metabolic rate and activity in adult Atlantic salmon, Salmo salar. J Fish Biol 44:889-903.

Lucas M.C., A.D.F. Johnstone, and I.G. Priede. 1993. Use of physiological telemetry as a method of estimating metabolism of fish in the natural environment. Trans Am Fish Soc 122:822-833.

Lucas M.C., I.G. Priede, J.D. Armstrong, A.N.Z. Gindy, and L. De Vera. 1991. Direct measurements of metabolism, activity and feeding behaviour of pike, Esox lucius L., in the wild, by the use of heart rate telemetry. J Fish Biol 39:325-345.

Packard G.C. and T.J. Boardman. 1999. The use of percentages and size-specific indices to normalize physiological data for variation in body size: wasted time, wasted effort? Comp Biochem Physiol 122:37-44.

Parsons G.R. and J.L. Sylvester Jr. 1992. Swimming efficiency of the white crappie, Pomoxis annularis. Copeia 1992:10331038.

Priede I.G. and P. Tytler. 1977. Heart rate as a measure of metabolic rate in teleost fishes: Salmo gairdneri, Salmo trutta and Gadus morhua. J Fish Biol 10:231-242.

Priede I.G. and A.H. Young. 1977. The ultrasonic telemetry of cardiac rhythms of wild brown trout (Salmo trutta L.) as an indicator of bio-energetics and behaviour. J Fish Biol 10: 299-318.

Randall D.J. 1968. Functional morphology of the heart in fishes. Am Zool 8:179-189.

Rowland S.J. 1989. Aspects of the history and fishery of the Murray cod, Maccullochella peelii (Mitchell) (Percichthyidae). Proc Linn Soc NSW 111:201-213.

- 1998. Age and growth of the Australian freshwater fish Murray cod, Maccullochella peelii peelii. Proc Linn Soc NSW 120:163-180.

Satchell G.H. 1991. Physiology and Form of Fish Circulation. Cambridge University Press, Cambridge.

Stevens E.D. and D.J. Randall. 1967. Changes in gas concentrations in blood and water during moderate swimming activity in trout. J Exp Biol 46:329-337. 
Taylor S.E., S. Egginton, and E.W. Taylor. 1996. Seasonal temperature acclimatisation of rainbow trout: cardiovascular and morphometric influences on maximal sustainable exercise level. J Exp Biol 199:835-845.

Thorarensen H., P.E. Gallaugher, and A.P. Farrell. 1996. The limitation of heart rate as a predictor of metabolic rate in fish. J Fish Biol 49:226-236.
Webber D.M., R.G. Boutilier, and S.R. Kerr. 1998. Cardiac output as a predictor of metabolic rate in cod Gadus morhua. J Exp Biol 201:2779-2789.

Woakes A.J., P.J. Butler, and R.M. Bevan. 1995. Implantable data logging system for heart rate and body temperature: its application to the estimation of field metabolic rates in Antarctic predators. Med Biol Eng Comput 33:145-151. 